\title{
Current Solid Waste Management Practices and Problems in Woliata Sodo Town, Southern Ethiopia
}

\author{
SOLOMON, SS
}

\author{
Hawassa University, College of Natural and Computational Sciences, Department of Biology, Hawassa, P. O Box 49, Ethiopia \\ Corresponding author Email: sorsasota@yahoo.com; Tel. = +251916828248
}

\begin{abstract}
The aim of this study was to assess the existing solid waste management (SWM) practices and problems in Wolaita Sodo town by collecting data using structured questionnaire and checklist. A cross-sectional design and a multistage sampling method was employed to select representative households (HHs) and purposive sampling technique was used to select Key Informants (KIs). A total of 408 respondents ( $378 \mathrm{HHs}$ and $30 \mathrm{KIs}$ ) participated in the study. The results indicated that the places where community containers located were not appropriate $(93.0 \%$ of $\mathrm{HHs}$ ), waste collection containers were not enough (100\%) and had no cover (28.0\%). Only half of HHs had access to SW collection service. All study participants reported the presence of open type waste transporting facility at the municipality level but $83.3 \%$ of KIs and $97.0 \%$ of HHs indicated absence of known fixed schedule for transporting the collected waste. The methods of disposal used include open burning (27.0\%), burying in the ground (5.4\%) and open dumping outside disposal site of the town (78.4\%). Nearly three-quarters of KIs reported the absence of responsible body to control and manage the open disposal site. Among the 17 major SWM problems listed by KIs, $12(70.6 \%)$ were rated as very serious and these were reported by about $87.0 \%$ of the KIs. The study revealed that the SWM practices and services at both HH and municipality level of Wolaita Sodo town was weak in terms of status as well as spatial coverage and service delivery is entangled by many very serious problems. Therefore, the town municipality must develop an appropriate SWM plan and implement it to improve the services, raise public awareness to increase participation in practices, increase stakeholders' involvement and enforce regulations and laws.
\end{abstract}

\section{DOI: https://dx.doi.org/10.4314/jasem.v22i7.17}

Copyright: Copyright (C) 2018 Solomon. This is an open access article distributed under the Creative Commons Attribution License (CCL), which permits unrestricted use, distribution, and reproduction in any medium, provided the original work is properly cited.

Dates: Received: 21 May 2018; Revised: 20 July: 2018; Accepted: 21 July 2018

Keywords: Woliata Sodo, Solid Waste, SW management, SW management practice, waste disposal

According to ENPHO (2008), if solid waste (SW) is not effectively managed; it can result in serious adverse impacts on environment and public health. Therefore, solid waste management (SWM) is a critical component within urban sanitation and it is also one of the most important and resource intensive services provided by municipalities. Municipal solid waste management (MSWM) is one of the basic services that are currently receiving wide attention in many cities and towns of Ethiopia. However, studies conducted in most major towns and cities of Ethiopia indicated that SWs that are generated are not appropriately handled and managed, mainly due to institutional, regulatory, financial, technical and public participation problems(Lema,2007; Melaku, 2008; Dereje, 2009; Nigatu et al., 2011; Solomon, 2011; Mekonnen, 2012; Dagnew,et al, 2012; Mengist and Assegid, 2014; Afework, 2015).

Planning for and implementing a comprehensive program for waste collection, transport, and disposal along with activities to prevent or recycle waste can eliminate MSWM problems (USEPA, 2002).
Therefore, it is possible to minimize and solve these problems in our towns/cities through strict planning and implementing different MSW components and options. But planning comprehensive SWM program requires understanding the existing SWM practices and problems in towns/cities. Although the population is rapidly increasing and the town is fast growing (Sodo City Administration, 2014), such practices and problems have not been well studied in Sodo town. The major objective of this study was therefore; to assess the existing SWM practices at $\mathrm{HH}$ and municipality level and SWM problems of Woliata Sodo town.

\section{MATERIALS AND METHODS}

Study area and population: Wolaita Sodo town, the administrative capital of the Wolaita Zone in Southern regional State of Ethiopia, is located $390 \mathrm{Km}$ South and $167 \mathrm{Km}$ of South West of Addis Ababa and Hawassa, respectively. The town is located $6^{0} 49^{\prime}$ N latitude and $37^{\circ} 45^{\prime \prime} \mathrm{E}$ longitude. Currently, the total area of the town is about 3,200 hectares and is divided in to three sub town ("Kifle-ketema"), namely Arada, 
Mehal Ketema and Merkato; and eleven "kebeles" (administrative units) and 99 villages ("mender"). Based on the 2010 census, the town has a total population of 110,660 (male 58,407 and female $52,252)$ with the projected annual growth rate of $4.8 \%$ (CSA, 2014). According to town administration report of 2014 (Sodo City Administration, 2014), the number of population is increasing at high level due to continuous rural-urban migration. The town connects commercially important zonal capital such as Arbaminich (capital of Gamo Zone), Sawulla (capital of Gofa Zone), Hosanna (capital of Hadiya Zone), and Shashemane town (capital of Western Arsi Zone).

Study design, sampling procedure and sample size determination: Cross-sectional descriptive survey design and both qualitative and quantitative methods were used in the study. The quantitative study method was used to collect data on demographic characteristic of the study participants (respondents); SWM practice and the effectiveness and efficiency of SWM system in the town. Qualitative method employed was observation that was used to observe and record waste management practices (collection, transportation, disposal, etc) of the public and municipality in the town. The study employed a multistage sampling method including stratified random sampling and systematic random sampling to identify or select the study sites and HHs, and purposive sampling technique to select Key Informants (KIs).

The three sub towns of Sodowere considered as strata that were used for stratified sampling. From the three sub towns a total of five administrative units ("kebeles") were randomly selected, namely: Merkato Gebeya, Fana, Damota, Wadu, and Kidane Mihret. The study participants HHs were randomly picked from the sampling frame using systematic random sampling method. In this study households who lived in the town for one year or longer were considered. For the survey, sample sizes (n) of HHs who participate in the study were determined using the population proportion formula developed by Cochran (1977) with the desired degree of precision for general population. Therefore, sample size calculation gave a total of 378 household respondents and these were drawn by random sampling method from a sampling frame.

A total of $30 \mathrm{KIs}$ were purposely selected to participate in the study based on their wide exposure to SWM issues, the position they held in the community, their proximity to appreciate the problems of SWM. These included road SW sweepers; private waste collector association members; waste management/ environmental experts from the town municipality; public health officers; health extension workers; "kebele" administrators; town administration officials; Wolaita Sodo university teachers; and Technical and Vocational Education training (TVET) college teachers.

Data collection tools: A semi-structured questionnaire with both closed and open - ended interview questions were used and the interview was carried out by researchers in the house of the HHs. To collect data from KIs, a structured individual questionnaire was used, self-administered and collected back by the researcher. To insure data quality, all the questionnaires were prepared in English language and were translated into Amharic (the national language) and a back translation was made by an independent person. Pre-test of questionnaire was also conducted and any problems in the content of the questionnaires were resolved during the pre-test.

Observation data were collected using checklist and it was conducted by the researcher at $\mathrm{HH}$ level and on different sites at field in the town. Observation involved watching and recording what people say and do and at household level it included onsite handling and collection of SWs, transport and disposal methods, etc. In the field/town observation was made to look into waste management practices along the road, drainage canals, municipality dustbins, open spaces, business areas, and market place. In addition, the town disposal site (fencing, guarding, etc) and the waste transport system of municipality and a private association were observed.

Data Management: Statistical analysis of data was carried out using SPSS version 20.0 statistical package program. Data were recorded, organized and summarized in simple descriptive statistics methods and mean, percentage, frequencies and range were used to describe the findings. One-way ANOVA was performed to assess whether there is a significant difference in response of $\mathrm{HHs}$ with respect to some selected demographic variables. The recorded observation data was put in order, reduced, classified and summarized for ease of interpretation and drawing conclusions separately and in connection to findings from quantitative study.

Ethical considerations: Ethical clearance was obtained from the Ethical Clearance Committee of Hawassa University. Before entering the study area to collect data, local authorities and community leaders were briefed about the objective of the study. Respondents participated in the study was voluntary and each respondent was asked to give verbal consent to participate and each household was assured that the information provided will be kept confidential. 


\section{RESULTS AND DISCUSSION}

Socio demographic characteristics of the study participants: A total of $378 \mathrm{HHs}$ were included in the study and among them $211(55.8 \%)$ were males and $167(44.2 \%)$ were females. Majority (78\%) of the respondents was within age group of 15-64 years and $22.0 \%$ of them were above 65 . Almost half $(51.3 \%$ ) of HH completed secondary school, $32.0 \%$ completed primary school and only $8.2 \%$ and $6.9 \%$ were college/diploma and first degree and above holders, respectively (Table 1$)$. About a third $(31.5 \%)$ of $\mathrm{HHs}$ reported being merchants (traders) and the other occupations include private employee (24.6\%), daily laborers (14.6\%), civil servants $(11.9 \%)$ and others (5.2\%). However, about $12.0 \%$ of the respondents were unemployed at the time of the survey (Table 1).

A total of 30 KIs had participated in the study and among them $16(53.3 \%)$ were females while 14 $(46.7 \%)$ were males. Ninety percent of them were within age range of 15-64 years and the remaining were above age 65 years. The majority of study participants KIs $(73.3 \%)$ were first degree and above holders. About $17.0 \%$ were college diploma holders, $6.7 \%$ and $3.3 \%$ completed primary and secondary schools, respectively (Table 1). Concerning job position of KIs 4 (13.3\%) were road SW sweepers; 4 $(13.3 \%)$ private waste collector association members; $3(10.0 \%)$ waste management/ environmental experts from the town municipality; $3(10.0 \%)$ public health officers; $4(13.3 \%)$ health extension workers; 5 (16.7\%) "kebele" administrators; 2 (6.7\%) town administration officials; $3(10.0 \%)$ university teachers and $2(6.7 \%)$ TVET college teachers.

Storage and on-site handling practice of SW Large majority $(82.0 \%)$ of the HHs use synthetic sacs ("Madaberiya") for onsite (primary) storage of waste, followed by plastic containers (11.2\%) including plastic (polythene) bags, old buckets (4.1\%), bamboo made containers $(1.4 \%)$ and a small proportion $(1.3 \%)$ of the HHs do not use any storage container (Figure 1). According to Kum et al. (2005), a key aspect of effective waste management is proper waste storage on the premises where the waste is generated. The survey (Figure 1) and observational results of the present study showed that for primary on-site storage of SW, HHs use different types of containers, which is expected to be for different reasons as described by Techobanglous et al., (1993). Large majority (82.0\%) of the HHs used synthetic sacs and this is expected to be due to easily availability in the market, the lowest cost, suitability for holding large volume of solid wastes, and low frequency and spatial coverage of door to door solid waste collection service of the town.
As described by Solomon Cheru (2011), plastic bag and basket use might be because of their frequent but low generation of waste and economical power to utilize replicable storage materials. Some of those who do not use containers were observed to store the waste in private pit in their compound and might be due to availability of space in their compound and households need to prepare composite/fertilizer for vegetable growing. Majority of the respondents (70.0\% of KIs and $93.0 \%$ of HHs) reported that the currentplaces where community containers located in the town are not appropriate sites. The entire study participants (both KIs and HHs) reported that the number of collection containers located in the town was not enough to collect thegenerated SW (Table 2).This result indicated that only about $17.0 \%$ of $\mathrm{HHs}$ had access to the community waste collection containers at the time of the study. This is two times more than that reported for Adama town (Lema, 2007).Consistent with our observation result, the reason for such gap might be due to inappropriate location of containers and long distance from $\mathrm{HHs}$ in most part of the town and therefore wastes were illegally thrown anywhere in the town. Therefore, the SWM facilities and secondary storage services provided by the municipality was not adequate and satisfactory.

About $28.0 \%$ of the HHs reported the presence of community containers with cover, and this is nearly two times greater than the $10.2 \%$ of Hosanna town (Mekonnen, 2012). But all the KIs deny the presence of such storage facility at the $\mathrm{HH}$ as well as municipal levels. In another way, our study showed that $72.0 \%$ of HHs use containers without cover which also indicates a poor onsite handling practice of SWs in Sodo. Such poor handling practice may cause multiplication of flies and vermin that can transmit diseases, and also compromise public and environmental health.

Large proportion (89.5\%) of HHs and half of the KIs reported that the community containers fill up within 3 days. But about a third (36.6\%) of KIs indicated filling up of the containers within 2 days (Table 2).

Waste reuse and compositing practices: Results (Table 3) of the present study revealed that only 17.7\% of HHs practiced SW sorting and KIs reported the absence of such practices at municipality level of Sodo town. This is consistent with finding of Adama town (Lema, 2007; Mengist and Assegid, 2014); Hosanna town (Mekonnen, 2012); Hawassa city (Dereje, 2009); Addis Ababa (Nigatu et al., 2011) and Jimma town (Melaku, 2008); Mekele city (Dagnew et al., 2012). 
Observation of HHs confirmed that only SWs that can be sold, exchanged and, to limited extent, organic wastes are separated. Types of items observe to be sorted by HHs include worn out clothes; old shoes; metals, tin and cans; plastics glasses, bottles, and some electronic wastes. Forty one percent of HHs practiced direct reuse of SWs at home level but all KIs reported the absence of such practice at municipality level and no such program was planned and/or lead (Table 3). This indicates that $59.0 \%$ of the HHs in Sodo town not exercising waste reuse at home level and this is in line with the finding of the study in Adama town (Lema, 2007). All respondents (HHs and KIs) reported the absent of onsite grinding and shredding practice (Table 3). This is expected to hinder participation of HHs on SW volume reduction practice that would increase the life span of final disposal site of the town.

Table 1. The Socio-demographic characteristics of study participants (HHs and KIs).

\begin{tabular}{llll}
\hline Socio-demographic characteristics & $\begin{array}{l}\text { HHs } \\
(\mathrm{n}=378)\end{array}$ & $\begin{array}{l}\text { KIs } \\
(\mathrm{n}=30)\end{array}$ \\
\cline { 3 - 4 } & & $\begin{array}{l}\text { Frequency } \\
(\boldsymbol{\%})\end{array}$ & $\begin{array}{l}\text { Frequency } \\
(\boldsymbol{\%})\end{array}$ \\
\hline Sex & Female & $167(44.2)$ & $16(53.3)$ \\
& Male & $211(55.8)$ & $14(46.7)$ \\
Age (years) & & & - \\
& 15 & - & - \\
& & $295(78.0)$ & $27(90.0)$ \\
Educational & No formal education & $83(22.0)$ & $3(10.0)$ \\
& Primary school (grades 1-8) & $6(1.6)$ & - \\
& Secondary school (grades 9-12) & $121(32.0)$ & $2(6.7)$ \\
& College Diploma & $26(6.9)$ & $1(3.3)$ \\
& First degree and above & $31(8.2)$ & $22(73.3)$ \\
Occupation & Civil servant & $45(11.9)$ & - \\
& Private employed & $93(24.6)$ & - \\
& Traders/merchants & $119(31.5)$ & - \\
& Daily laborers & $55(14.6)$ & - \\
& Unemployed & $46(12.2)$ & - \\
& Others & $20(5.2)$ & - \\
\hline
\end{tabular}

Note: The value in parenthesis is percent of the total

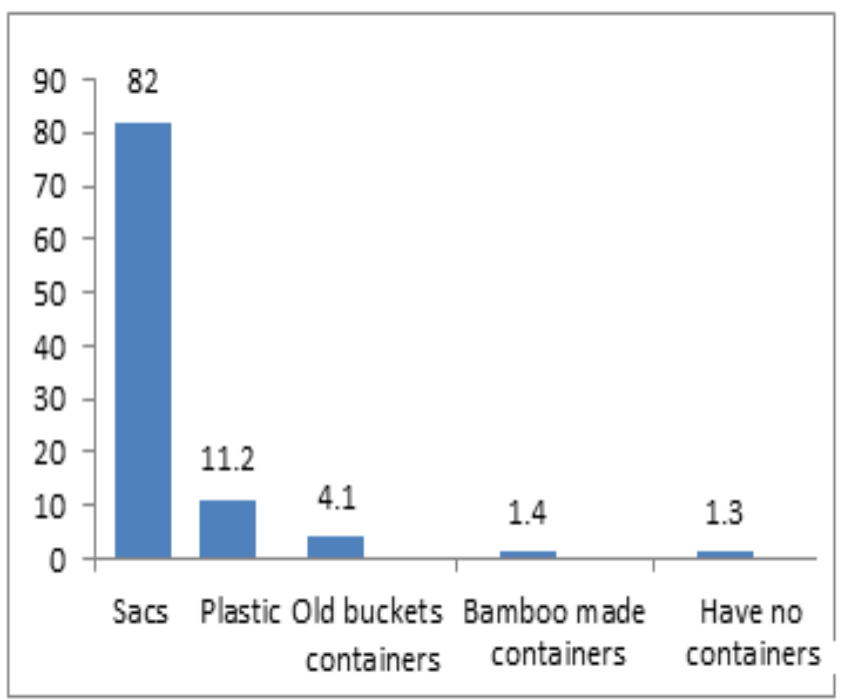

Fig 1. Household's SWs onsite storage containers and its usage by percent.
Only $3.5 \%$ of HHs are doing home composting at the time of the study and from the remaining $2.0 \% \mathrm{HHs}$ had no idea about compositing. However, all the KIs testified the absent of compositing practice at municipality levels(Table 3).Even though Endriasand Solomon (2017) currently reported about $71.2 \%$ of SWs generated by $\mathrm{HH}$ in Sodo town were easily decomposable organic wastes, the present study revealed that larger portion of HHs were not interested to practice home composting. In terms of recycling, none of the respondents mentioned it and there isno compositing program/plan at town municipality level as reported by KIs (Table 3).Similar to the present study finding; study reports from Adama town (Lema, 2007; Mengist and Assegid, 2014); Hawassa city (Dereje, 2009); Hosanna town (Mekonnen, 2012); Mekele city (Dagnew et.al., 2012) also showed the absence of composting practice at municipality level. However; unlike this, the study in Bahir Dar city reported using about $2.0 \%$ of waste to produce compost at the city service compost site (FFE, 2010). In general, the main reason behind low practice of sorting and reusing, and absence of recycling activities of the society in Sodo town seems to be due to lack of awareness about sustainable SWM practices, their less interest and very low economic feasibility of reusable and recycled materials.

The absence of such activity at municipality level might be attributed to lack of commitment, finance, material, and manpower resource. Furthermore, to fill this gap the municipality has not also played any role in organizing, encouraging, and giving incentives to different stakeholders such as informal workers, private investors, NGOs, and community members to participate in such activities. 
Table 2. Community (secondary) SW storage site handling practice at HH level and town level (as reported by KIs)

\begin{tabular}{llccccc}
\hline \multicolumn{1}{c}{ Variables } & & \multicolumn{2}{c}{$\begin{array}{c}\text { HHs resp onse } \\
\text { (n=378) }\end{array}$} & \multicolumn{2}{c}{$\begin{array}{c}\text { KIs response } \\
(\mathbf{n}=\mathbf{3 0})\end{array}$} \\
\cline { 3 - 7 } & & Frequency & $\%$ & Frequency & $\%$ \\
\hline Community container placed & Yes & 27 & 7 & 9 & 30 \\
in appropriate location & No & 351 & 93 & 21 & 70 \\
The number of community & Enough & - & - & - & - \\
waste containers located & Not enough & 378 & 100 & 30 & 100 \\
Community storage & With cover & 105 & 27.8 & - & - \\
containers & Without cover & 273 & 72.2 & 30 & 100 \\
Frequency of containers filled & Every day & - & - & - & - \\
with SW & 2 days & - & - & 11 & 36.6 \\
& 3 days & 338 & 89.5 & 157 & 50 \\
& 4 days & 40 & 9.5 & 4 & 13.4 \\
\hline
\end{tabular}

Note: KIs response represents the practice at municipality/town level

Table 3. Solid waste reduction methods practice in Sodo town at HH and municipality levels

\begin{tabular}{llcccc}
\hline \multicolumn{2}{c}{$\begin{array}{c}\text { SW reduction methods } \\
\text { practices }\end{array}$} & \multicolumn{2}{c}{ HHs $(\mathbf{n = 3 7 8})$} & \multicolumn{2}{c}{ KIs $(\mathbf{n = 3 0})$} \\
\cline { 2 - 6 } & & Frequency & \% & Frequency & \% \\
\hline Sorting in a separated & Yes & 67 & 17.7 & - & - \\
containers & No & 311 & 82.3 & 30 & 100 \\
Onsite grinding and & Yes & - & - & - & - \\
shredding & No & 378 & 100 & 30 & 100 \\
Direct reusing & Yes & 155 & 41.0 & - & - \\
\multirow{2}{*}{ Composting } & No & 223 & 59.0 & 30 & 100 \\
& Yes & 13 & 3.5 & - & - \\
& No & 357 & 94.5 & 30 & 100 \\
& No idea & 8 & 2.0 & & - \\
\hline
\end{tabular}

Table 4. Type of waste collection and transportation services delivered to HHs by the municipality as reported by HHs and KIs.

\begin{tabular}{|c|c|c|c|}
\hline \multicolumn{2}{|l|}{ Services } & HHs $(\mathrm{n}=378)$ & $\begin{array}{c}\mathrm{KI} s(\mathrm{n}=30) \\
\text { Frequencv }(\%)\end{array}$ \\
\hline \multirow{4}{*}{$\begin{array}{l}\text { Community container } \\
\text { collection } \\
\text { Door to door collection }\end{array}$} & Available & $65(17.2)$ & $4(13.3)$ \\
\hline & Not available & $121(32.1)$ & $26(86,7)$ \\
\hline & Available & $126(33.3)$ & $8(26.7)$ \\
\hline & Not available & $66(17.4)$ & $22(73.3)$ \\
\hline \multirow[t]{2}{*}{ Block collection } & Available & - & - \\
\hline & Not available & $378(100)$ & $30(100)$ \\
\hline \multirow{6}{*}{$\begin{array}{l}\text { Closed type SW transport } \\
\text { facility/ services available } \\
\text { Frequency of waste } \\
\text { transportation }\end{array}$} & Yes & - & - \\
\hline & No & $378(100 \%)$ & $30(100 \%)$ \\
\hline & Once/week & $15(4.0 \%)$ & \\
\hline & Twice/week & - & $14(47.0 \%)$ \\
\hline & Three times/week & - & $16(53.0 \%)$ \\
\hline & $\begin{array}{l}\text { Stay longer ( } 4-5 \\
\text { days) }\end{array}$ & $363(96.0 \%)$ & - \\
\hline $\begin{array}{l}\text { Presence of timetable for waste } \\
\text { transportation from collection } \\
\text { site }\end{array}$ & $\begin{array}{l}\text { Yes } \\
\text { No }\end{array}$ & $\begin{array}{l}11(3.0 \%) \\
367(97.0 \%)\end{array}$ & $\begin{array}{l}5(16.7 \%) \\
25(83.3 \%)\end{array}$ \\
\hline
\end{tabular}

Note: The value in parenthesis is percent of the total $S W$ transport delivery service

Waste Collection and transportation practices: Observation results revealed that in the town, collection and transportation services were provided by the municipality and only one formal sector (waste collectors association). Small proportion of respondents $(17.2 \% \mathrm{HHs}$ and $13.3 \% \mathrm{KIs})$ reported the availability of community container collection and only about a third (33.3\%) of HHs and $26.7 \%$ of KIs indicated availability of door to door waste collection services for $\mathrm{HHs}$ in the town. Furthermore, all study participants (KIs and HHs) agree on the absence of block collection service in the town (Table 4). The door to door waste collection service access of Sodo town reported by HHs is about 5-times greater than that of Hosanna town (Mekonnen, 2012) and Adamatown (Lema, 2007). However, observation revealed that door to door collection of municipality truck reached only to very few residents who are situated in central part of the town and along the main roads. Therefore, the HHs demands were not satisfied due to inefficiency of current services delivery system. Therefore, the study revealed that only half $(50.5 \%)$ of the HHs had access to SW collection service in the town $(17.2 \%$ container collection plus $33.3 \%$ door to door), indicating the remaining half of the waste remains uncollected.

This study result is also in line with the reports of Ministry of Urban Development and Construction of Ethiopia (FMOUDC, 2012) that reported 30 to $50 \%$ of SW produced in urban areas in Ethiopia is left uncollected. Lower than the present study results (Table 4), only $40.0 \%$ of SWs were collected in Debre Markos town (Pananjay and Tiwari, 2012), 50.0\% in Mekele city (Mekele Municipality, 2008). But daily about $70.0 \%$ of the generated MSW is collected and disposed in Bahir Dar city (FFE, 2010). All of respondents (KIs and HHs) reported the presence of open type waste transporting facility at the municipality levels that is used to transport SW to the final disposal site of the town (Table 4).

This result is in agreement with that of observation that indicated the municipality has only 2 trucks (open type). Similar practice was reported in Bahir Dar town (FFE,2010); in Adama town (Lema,2007; Mengist and Assegid,2014); in Hosanna town (Mekonnen,2012); in Hawassa city (Dereje,2009); in Addis Ababa (Nigatuet al., 2011), in Jimma (Melaku,2008);and also in Mekele city (Dagnewet.al., 2012). Concerning frequency of transport, large majority (96.0\%) of $\mathrm{HHs}$ reported that the waste collected, sometimes, may stay 4-15 days, but only $4.0 \%$ said waste was transported once per week. 
Table 5. SW disposal practices of HHs and municipality

\begin{tabular}{llll}
\hline SW disposal practices & Response & HHs $(\mathbf{n}=\mathbf{3 7 8})$ & KIs $(\mathbf{n}=\mathbf{3 0})$ \\
\hline HHs dispose in open pits & Yes & $81(21.4)$ & - \\
HHs open burning & Yes & $101(26.8)$ & $8(27.8)$ \\
HHs burying in the ground & Yes & $20(5.4)$ & $1(2.0)$ \\
HHs open dumping outside disposal site & Yes & $296(78.4)$ & $21(70.2)$ \\
Municipality dispose at open disposal site & Yes & $378(100)$ & $30(100)$ \\
Municipality dispose at sanitary land fills & Yes & - \\
Presence of responsible body to manage disposal site & Yes & - & $8(27)$ \\
& No & - & $22(73)$ \\
Appropriateness of disposal site in terms of location and properly & Appropriate & - & - \\
management & Not appropriate & - & $30(100)$ \\
Management of disposal site to reduce environmental risks/problems & Proper & - & - \\
& Not proper & - & $30(100)$ \\
\hline
\end{tabular}

Note: The value in parenthesis is percent of the total $S W$ disposal practice

Table 6. Problems related to SWM and their level of difficulty as reported by KIs $(n=30)$

\begin{tabular}{|c|c|c|c|c|}
\hline \multirow[t]{2}{*}{ Problems reported } & \multicolumn{4}{|c|}{ Level of difficulty } \\
\hline & 1 & 2 & 3 & 4 \\
\hline Inadequate service coverage & $\mathrm{X}$ & & & \\
\hline Lack of quality and satisfactory WM service & $\mathrm{X}$ & & & \\
\hline Lack of fast financial and administrative decision & & & $X$ & \\
\hline Lack of budget (financial resources) & $\mathrm{X}$ & & & \\
\hline Lack of trained/skilled manpower (human resource) & & & $\mathrm{X}$ & \\
\hline Lack of equipment and vehicles (material resource) & $X$ & & & \\
\hline Improper/inadequate institutional set-up/arrangement for SWM service & & $\mathrm{X}$ & & \\
\hline Lack of WM planning (short, medium and long term strategy) & $\mathrm{X}$ & & & \\
\hline Lack of appropriate rules and regulations/legislation and their re-enforcement & & & & $\mathrm{X}$ \\
\hline Poor socio economic status of the residents & $\mathrm{X}$ & & & \\
\hline Rapid urbanization outstripping service capacity & $\mathrm{X}$ & & & \\
\hline Socio-cultural and religious effects & $\mathrm{X}$ & & & \\
\hline Poor community participation and cooperation & $\mathrm{X}$ & & & \\
\hline Poor response to waste reduction (reuse/recycling) & $\mathrm{X}$ & & & \\
\hline Information gaps and low level of public awareness & $\mathrm{X}$ & & & \\
\hline Poor cooperation of government agencies/stakeholders & $\mathrm{X}$ & & & \\
\hline Lack of qualified private contractors & & & $\mathrm{X}$ & \\
\hline Total & 26 & 3 & 17 & 1 \\
\hline Percentage* & 86.7 & 10 & 56.7 & 3.3 \\
\hline
\end{tabular}

Note: $1=$ Very serious; $2=$ Serious $; 3=$ Not so serious; $4=$ No problem; $*$ More than one response is possible and therefore, sum of percentages may be greater than a hundred.

However, $53.0 \%$ of KIs claimed that the waste was transported "three times per week", while $47.0 \%$ of them said "twice per week. A majority (83.3\%) of KIs and HHs $(97.0 \%)$ reported that there is no plan or no known fixed schedule for transporting the collected SW to disposal site (Table 4). Observation results revealed that most of HHs family members had to travel more than $150-550$ meters to reach the nearest containers to dump their SW. This might have discouraged dumping $\mathrm{SW}$ in the community containers, but encouraged unauthorized or illegal disposal anywhere. Therefore; as described by EGSSAA, (2009), irregularity of waste removal from the containers after filling and long distance from containers might have negatively influenced the SWM services. Although collection and transportation are functional elements that are very crucial and compulsory component of municipal SWM, present study indicated that HHs SW is not properly and continually collected on the right time, i.e. the services do not cover all the corners of the town due to inadequate facilities and budget, and shortage of man power. Consistent with the present study, ENDA (2006) reasoned out that most of the waste collection and transportation services often administered only by the government/town municipality, with no or little involvement of private sectors. This shows that the collection and transportation services need improvement in order to address the problems of SWM of the town.

Solid waste disposal practice: The result (Table 5) indicated that $21.4 \%$ of $\mathrm{HHs}$ dumping their SW in open disposal pits located in their compound; about $28.0 \%$ of KIs and $27.0 \%$ of HHs reported practicing "open burning", and only $5.4 \%$ of $\mathrm{HHs}$ and $2.0 \%$ of KIs reported burying in the ground. However, the majority of respondents $(70.2 \%$ of KIs and $78.4 \%$ of $\mathrm{HHs}$ ) reported often practicing open dumping outside disposal site of the town (Table 7). All the respondents confirmed that the municipality uses only open disposal site for dumping and there is no sanitary land fill in the town (Table 5). The HHs practiced open burning in the present study are nearly 10 times more than that in Debre Berhan city (2.7\% of HHs)(Vikrant et al., 2014). Uncontrolled burning of waste is expected to contribute to urban air pollution. According to Cunningham (2008), proper SWM requires proper disposal of wastes in a proper place. However, this study showed that the majority of respondents (70.2\% of KIs and $78.4 \%$ of $\mathrm{HHs}$ ) (Table 5 ) practice open dumping outside disposal site of the 
town and this is in agreement with that reported (75\% of HHs) from Debre Berhan city (Vikrant etal., 2014). Statistical test (ANOVA) indicated that more males than females; younger age group than older age group practiced an open dumping. Open dumping practice is negatively correlated with educational level of respondents. Observation of residential area and $\mathrm{HH}$ survey results confirmed that the destination of the majority of uncollected solid wastes of HHs are roads, nearby ditches, back yard of the houses, bridges, and open areas. This improper disposal of SW is an immediate risk factor of environmental pollution.

Nearly three-quarters $(73.0 \%)$ of KIs reported the absence of responsible body to control/monitor and manage the final disposal site and all KIs reported that the waste disposal site of Sodo town is not in appropriate place (Table 5). Through observation, it is also confirmed that management of town disposal site is very poor because it does not have any fence or cover that protects animals and people from entering into the site and SW dispersal to the surrounding community by wind blow and runoff. This poor disposal site management is expected to pollute and negatively affect the nearby environment, the peoples living near the area, the nearby agricultural area, and animals, etc. Therefore, the existing disposal site is not in appropriate place and should be changed and well managed. Although conventional methods such as open-burning, open dumping, and non-sanitary landfill can still be used as disposal method (UNEP, 2009), they are environmental unfriendly. Particularly, as Sodo is a fast growing town and becoming overpopulated, the municipality has to think of selecting appropriate site and replacing the current open dump sites more environmental friendly disposal method such as sanitary landfill.

Problems of SWM in Sodo town: Among the 17 major SWM problems listed, 12 (70.6\%) were rated as very serious and these were reported by about $87.0 \%$ of the KIs (Table 6). The very serious problems stated by KIs include lack of regular frequency of waste collection and transport service, lack of financial resources and equipment, poor socio-economic status of the residents, lack of plan (short, medium and long term plan), poor community participation and cooperation, poor cooperation among government offices, sociocultural and religious effects, rapid urbanization and information gaps and low level public awareness.

These problems, among others, are expected to hold back the effective performance of SW management services in Sodo town. On the other hand, $10 \%$ of the study participant KIs also indicated that improper institutional set up/arrangement for SWM service was a serious problems (Table 6).The present study revealed that the existing SWM practices in Sodo town are entangled with very serious problems that are responsible for inefficient SWM system.

Conclusion: Findings of the present study clearly indicate that the SWM system in Sodo town is very weak and needs improvement. Therefore, the town administration/ municipality must work hard to make SWM system more efficient to improve the services, raise public awareness to increase their participation in practices, increase stakeholders' involvement and enforce SWM regulations, laws, etc., Moreover, there is a need to have well organized management that functions within an adequate institutional arrangement, skilled manpower and financial resources. Furthermore, the town municipality must develop an appropriate SW management plan and implement to properly manage the SW generated in Sodo town.

Acknowledgements: I would like to thank Sodo town municipality and administration for facilitating and overall cooperation during the study. I also thank the households and Key Informants for their cooperation during sample collection.

\section{REFERENCES}

Afewerk, B. (2015). Household generation rate and composition analyses in Adama town. MSc thesis, Haramaya University, Ethiopia.

Central Statistic Authority (CSA), Wolaita Branch. (2014). The 1999 Population projection of Sodo town, 2013/14 Statistical Abstract, Sodo, Ethiopia

Cochran, G. 1977. Sampling Techniques, 3rd edition, Wiley Series in Productivity and Applied Mathematical Statistics. New York, USA.

Cunningham, T. (2008). Principles of Environmental Science Inquiry and Applications. 4th edition, McGraw Hill International Edition, USA.

Dagnew, H; Alemu, M; Zenebe G. (2012). Households' willingness to pay for improved urban waste management in Mekelle city. Environment for Development, Discussion Paper Series April, 2012, EfD DP 12-06.

Dereje, D. (2009). Household solid waste generation rate, composition and content analysis for disposal and resource recovery in two selected kebeles of Hawassa town. MSc thesis, Addis Ababa University, Addis Ababa, Ethiopia, 
Endrias, G; Solomon SS. (2017).Generation rate and physical composition of solid waste in WolaitaSodo town, Southern Ethiopia; Ethiopian J. Environmental studies and Management, 10 (3): $415-42$.

Environment and Public Health Organization (ENPHO). (2007). Solid waste management in Nepal. 110/25

Adarsa Marga-1, Thapagaon, New Baneshwor, Kathmandu, Nepal. (Accessed date: 25 September 2012).

Environmental Development Agency (ENDA). (2006). Living Healthily in a Clean and Green City. Habitat International Coalition Case Study. Barcelona, Spain.

Environmental Guidelines for Small Scale Activities in Africa (EGSSAA). (2009). Solid waste generation, handling, treatment and disposal. USAID Africa Bureaus Environmental Compliance and Management Support (ENCAP) program.

Federal Ministry of Urban Development and Construction (FMOUDC), 2012. Solid waste management manual: With respect to urban plans, sanitary landfill sites and solid waste management planning. Urban Planning, Sanitation and Beautification Bureau April, 2012, Addis Ababa, Ethiopia.

Forum for Environment (FFE). (2010). Assessment of the solid waste management system of Bahir Dar town and the gaps identified for the development of an ISWM plan. In Ethiopian Environment Review. Addis Ababa.

Kum, V., Harnpornchail, N; Sharp, A. (2005). Improving waste management in Phnom Penh city: Strategic approach. Waste Management 25:101-109.

Lema, A. (2007). Household solid waste generation rate and composition analysis in two selected kebeles of Adama town, MSc thesis, School of Graduate Studies, Addis Ababa University, Addis Ababa, Ethiopia,

Mekelle Municipality. (2008). Six-Month Report 2007/2008 [2nd half of fiscal year 2007/2008], Mekelle, Ethiopia: MCA.
Mekonnen, A. (2012). Development of solid waste management strategy for Hossana town. MA thesis, Addis Ababa University, Addis Ababa, Ethiopia.

Melaku, T. (2008). Household solid waste generation rate and physical composition analysis, in Jimma town, Ethiopia.

Mengist, H; Assegid, A. (2014). Solid waste management in Adama, Ethiopia: Aspects and challenges. International Journal of Environmental, Chemical, Ecological, Geological and Geophysical Engineering 8 (9): 670-676

Nigatu, R; Sundaraa, R.D; Bizunesh, B. (2011). Challenges and opportunities in municipal solid waste management: The Case of Addis Ababa City, Central Ethiopia. Journal of Human Ecology33: 179-190.

Pananjay, KT; Tiwari, SC. (2012).An overview of Solid waste management system in Debre Markos town of Ethiopia. Global Journal of Current Research 1: 1-8

Sodo Town Administration. (2014). Woliata Sodo town administration annual report of 2014. Wolaita Zone, Sodo, Ethiopia.

Solomon, C. (2011). Assessment of municipal solid waste management service in Dessie town. MA thesis, Addis Ababa University, Addis Ababa, Ethiopia.

United Nations Environmental Program (UNEP). (2009). Developing integrated solid waste management plan: training manual for assessment of current waste management system and gaps therein, Volume 2,

Osaka/ Shiga, Japan. Retrieved from: http://www.unep.or.jp/ietc/publications/spc/ISW Mplan-vol2.pdf

Vikrant T., Solomon F, Sharma HR. (2014). Municipal solid waste management in Debre Berhan City of Ethiopia. Urban Management and Climate Change Department, Ethiopian Civil Service University, Addis Ababa, Ethiopia Vol. 4, No.5, 2014. 